\title{
Genetic predisposition to stomach ulceration in emotionally reactive strains of rats
}

\author{
A. A. MIKHAIL, University of Manitoba, \\ Winnipeg, Canada
}

$A$ simplified method of inducing ulceration by stress was applied to two strains of rats selectively bred for high and low emotionatity in the open-field test. Contrary to a previous report, the severity of stomach ulceration as assessed by a refined technique of stomach examination was found to be greater in the emotionally reactive strain (MR) than in the nonreactive strain (MNR). It was argued that the physiological mechanism underlying the higher emotional elimination of the MR strain reflects greater parasympathetic discharge of the sacral division under certain stressful conditions and that the parasympathetic hyperactivity may partly account for the genetic predisposition of the $M R$ strain to stress ulceration.

Clinical observations suggest a relationship between peptic ulceration and neurosis. Neuroticism, which is vulnerability to neurosis in humans, may be regarded as an analogue of emotionality in rats (Eysenck \& Broadhurst, 1964). Indeed, the lability and excitability of the autonomic nervous systems are involved in both of them. In addition, emotionality as judged by the number of fecal boluses in the open-field test has been found to be heritable (Hall, 1938; Broadhurst, 1960). This fact has been demonstrated by Broadhurst whose selective breeding procedures led to the development of two strains of rats which differ in emotionality, the Maudsley Reactive and Non-Reactive strains [MR and MNR (Jay, 1963) and 163f and $g$ (LAC Catalogue, 1958), respectively]. Generally, the reactive strain behaves in a more fearful, emotional manner, relative to the nonreactive strain, in the open-field test as well as in other situations (Eysenck \& Broadhurst, 1964).

In light of what has been mentioned, the hypothesis that the reactive strain (MR) would be more susceptible to stress-induced ulceration than the nonreactive strain (MNR) was advanced. This hypothesis was tested in a previous study (Mikhail \& Broadhurst, 1965). However, the procedure which was employed did not differentiate between the MR and MNR strains in ulceration. The present experiment aimed at testing the hypothesis further when a new method of inducing stomach ulceration and a more refined technique of stomach exam- ination (Mikhail \& Holland, 1966a, b) were employed.

\section{SUBJECTS}

Forty male rats, 20 of the MR strain and 20 of the MNR strain, were employed. They were chosen randomly from the Ss of the 26th generation $\left(S_{26}\right)$ of selection, 168-184 days of age, and averaged $282.9 \mathrm{~g}$ in weight. In addition to these Ss, 20 rats of 212-215 days of age served as a control group. In this group, both strains and sexes were equally represented. Details about the origin of the Maudsley strains, the open-field testing, and their selection for breeding are described by Broadhurst (1960). A brief mention is cited below.

In the open-field test the Ss were exposed in an arena, 323/4 in. in diam, to "white" noise of an intensity of $78 \mathrm{~dB}$ re 0.0002 dynes $/ \mathrm{cm}^{2}$, and to light of $165 \mathrm{ft}-\mathrm{c}$ at floor level for $2 \mathrm{~min}$ at approximately the same time of day on four successive days. Two main scores were obtained (1) the defecation score-by counting the number of fecal boluses deposited, and (2) the ambulation score-by counting the number of floor units entered. Testing the $S$ in the open-field situation was carried out when the animals were between 95 and 105 days of age.

Selection of potential parents for the nex generation was based on extreme defecation scores in the open-field test and was fol lowed by mating together within litters rats of high defecation scores and rats of low defecation scores. The animals of every new generation were reared under strict standard conditions. The room temperature was maintained at $70 \operatorname{deg} F \pm 2$ and the dark light cycle was regulated by automatic control so that light was off between 9 p.m. and 3:30 a.m. Weaning of the litters was carried out at 21 days after birth. When the animals were about 50 days of age their ears were clipped for identification. Rat food (M.R.C diet No. 41B), ad lib, and tap water were provided.

\section{PROCEDURE}

The experimental Ss were weighed and deprived of food for a period of $20 \mathrm{~h}$, i.e. from $2 \mathrm{p} . \mathrm{m}$. to $10 \mathrm{a} . \mathrm{m}$. The following day the rats were exposed to a stress treatment (Mikhail \& Holland, 1966a) for a period of $24 \mathrm{~h}$. Briefly, the stress treatment was as follows.

Corslets of plaster of Paris, measuring $3 \mathrm{~cm}$ in diam, $7 \mathrm{~cm}$ long, and $2 \mathrm{~mm}$ thick were prepared. When the corslet was dry, it was fitted around the abdomen and the lower part of the rat's thorax. To prevent the animal from shedding the corslet, three pairs of rubber bands were placed around it. The Ss were then housed individually in compartments measuring $12 \times 20 \times 18 \mathrm{~cm}$.
Water was allowed ad lib throughout the period of the experiment.

At the end of the stress period of $24 \mathrm{~h}$, the Ss were sacrificed by an overdose of ether anesthesia and their stomachs removed for examination. The control Ss did not receive any experimental treatment. The purpose of including this group was to find out whether gastric ulceration would develop spontaneously in rats, and if so, whether the MR strain would differ from the MNR strain.

\section{RESULTS}

The findings were as follows: (1) It was observed that ulcers developed mainly in the antrum of the stomach (Figs. 1, 3, and 4). The median number of ulcers was 6.0 for the MR strain and 3.7 for the MNR strain. A Mann-Whitney test showed that ulcer susceptibility in the MR rats is significantly greater than in the MNR rats $(U=98$, $p<.01)$. (2) Rarely, lesions of the characteristic shape and size shown in Fig. 2 developed in the corpus of the MR stomachs; they were never observed in the stomachs of the MNR strain. In a sample of 70 MR stomachs which included 20 of the present study, only five stomachs displayed this pathology compared with 0 out of 70 in the MNR stomachs $\left(\chi^{2}=3.32, p<.05\right)$. (3) No lesions were found in the stomachs of the group which was tested for spontaneously occurring ulceration. An evaluation of the results of studies on experimental ulceration requires the knowledge of the frequency of these lesions occurring spontaneously in the rat. There are observations that ulceration develops in rats without exposure to stress (Skoryna, 1963). These observations were attributed to nutritional factors in the diet used in some rat colonies.

\section{DISCUSSION}

Two points will be considered below: (1) the inheritance of peptic-ulcer predisposition; and (2) the nature of the hereditary predisposition to ulceration in the MR strain.

(1) The inheritance of peptic-ulcer predisposition. The greater ulcer susceptibility of the MR strain demonstrates the important influence of genetic factors on this pathology. Relatively little experimental work has been carried out to investigate the hereditary aspect of ulcer etiology. This is evidenced by the absence of a monograph on the genetics of peptic ulcer in Skoryna's (1963) symposium, Pathophysiology of the peptic ulcer. In the literature on ulceration in humans, it is not surprising to find that the contribution of this line of research is not substantial, since humans are usually impracticable subjects for genetic experimentation. In animal studies, strain and sex differences in ulceration were investigated by Sawrey and Long (1962) and Ader et al (1960). The former investigators, using a conflict procedure, found that Nebraskahooded rats, both males and females, and 

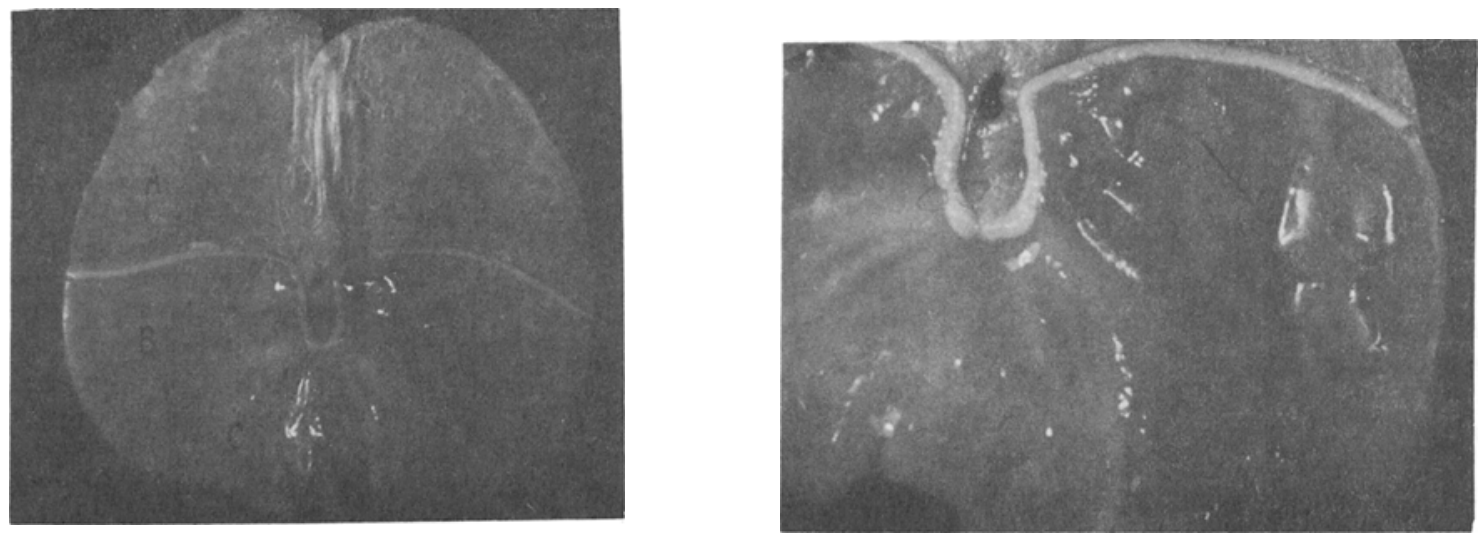

Fig. 1. The inner surface of a normal rat's stomach. The area around $A$ is the rumen, the nonsecretary portion of the stomach. The rumen, which does not contain gastric glands, is thinner than the glandular portion (B and C), translucent, and covered with stratified squamous epithelium. The areas around B (fundus) and C (antrum) constitute the body (corpus) of the stomach.

Fig. 2. A form of ulceration distinctive of the MR strain. The lesions were large (3.5 $\mathrm{mm}$ in diam) and had a punched-out appearance with exaggerated surrounding protrusions. They developed rarely $(7.1 \%)$ in the MR stomachs, but they never appeared in the MNR strain.
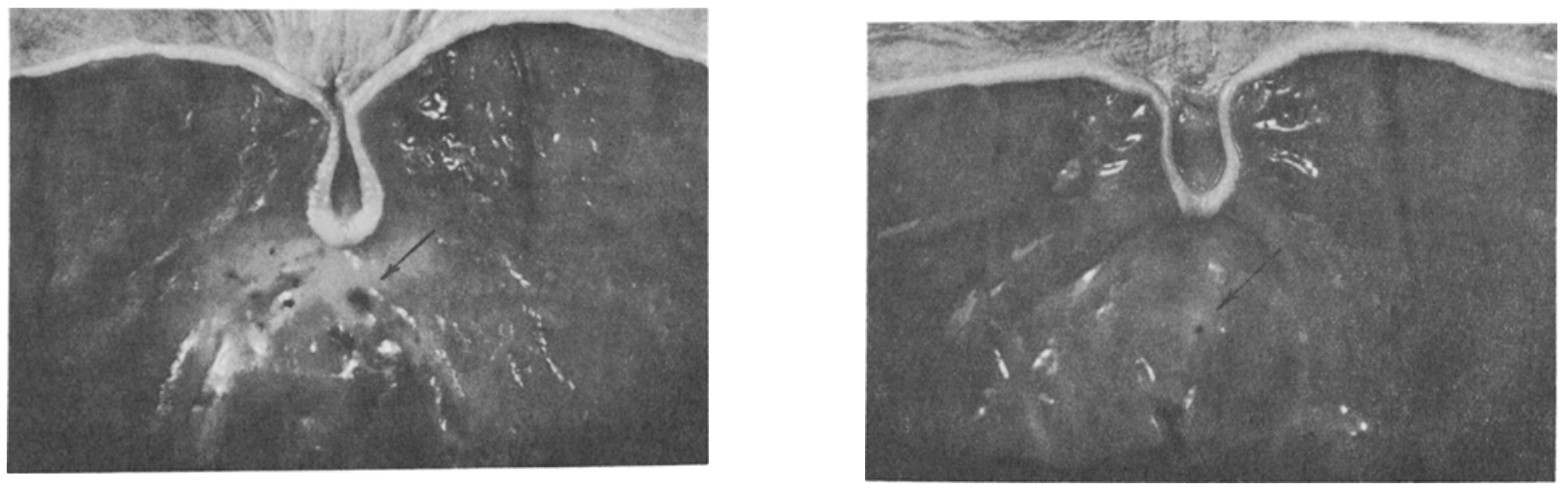

Fig. 3. Ulceration in the stomach of a rat of the MR strain. The lesions were confined to the antrum of the stomach.

Fig. 4. Relatively severe ulceration in the stomach of a rat of the MNR strain (cp. Fig. 3).

females of the Wistar strain were more ulcer resistant than rats of both Long-Evans and Sprague-Dawley strains. This result, however, was inconsistent with that of Ader et al (1960) who employed immobilization to induce ulceration.

Of considerable importance is Sines' (1959) demonstration that ulcer susceptibility in rats is amenable to selective breeding and was correlated with high emotionality (1962). This demonstration and the observation (Sines, 1962) that ulcer incidence in Sines' selectively bred strain of rats is greater than in other strains-Irish $\mathrm{AxC}$, Fisher 344, August 33322, SpragueDawley-provides evidence for hereditary factors influencing the development of stomach lesions under stress. A second source of evidence is furnished by the present study, namely that greater ulcer susceptibility is associated with the MR strain which has been selectively bred for greater emotionality. This finding not only supports the heritability of a predisposition to stomach ulceration, but it also throws some light on the possible nature of the predisposing influences.

(2) The nature of the hereditary predisposition to ulceration in the MR strain. There is an intimate relationship between emotionality in animals and the activity of the autonomic nervous system. Indeed, emotionality has been defined as "an inherited predisposition of the autonomic ner- vous system to react particularly strongly, quickly, and lastingly to certain classes of stimuli [Savage \& Eysenck, 1964]."Under stressful conditions emotional elimination is displayed not only in animals but also in humans as a result of autonomic activity of the parasympathetic. In this regard, Gellhorn \& Loofbourrow (1963) mentioned that "symptoms signifying increased parasympa the tic activity are likewise common in human emotions. Thus frequent urination and emptying of the rectum with loss of voluntary control of these functions occurs in more severe forms of emotional disturbances [p. 72] ."'

A brief account of the relationship between autonomic activity and emotional 
elimination is the following. The evacuation of the rectum of its contents is a reflex action which is partly a function of the sacral division of the parasympathetic system. In addition to reflex response produced by local distention of the rectum, involuntary defecation may result from emotional discharges over the sacral nerves (Lindsley, 1951). The role of the sympathetic system, as in many physiological functions other than defecation, is usually the reverse of the parasympathetic. Thus the sympathetic tends to cause retention of contents in the rectum, while the parasympathetic tends to promote evacuation of contents by causing relaxation of the sphincters and contraction and propulsive motility of the rectal walls. The foregoing account suggests that the greater emotional elimination of the MR strain in the open field is associated with a functionally active part of the parasympathetic system, i.e., the sacral division.

Furthermore, the relationship between the autonomic nervous system, in particular the parasympathetic division, and ulceration has long been established (Cushing, 1932). Recently, Francois \& Sines (1961), using an antiserum to a nerve growth protein which selectively reduces the number of cells in the sympathetic chain ganglia of newborn rats, found that the severity of restraint ulceration in rats so treated was greater than in control groups. They interpreted this result as "further support for the notion that parasympathetic dominance is involved in the susceptibility of the rat to immobilization induced stomach lesions." It is known that sympathetic influences are inhibitory to gastric function (Cannon, 1915). Hence, if the sympathetic activity were predominant in the MR rats, ulcer severity would have been lower in this strain. This was not born out by the result of the present study. From what has been cited it may be concluded that (1) the greater emotional elimination of the MR strain appears to reflect greater parasympathetic activity of the sacral division under certain stressful conditions, and that (2) the greater parasympathetic discharge may partly account for the predisposition of the MR strain to ulcer formation.

Follow-up studies wherein the MR and MNR strains were tested for stress-induced ulceration confirmed the findings of the present report. It is worth noting that a comparison of data obtained recently from about 150 Sprague-Dawley and Wistar rats with those of the Maudsley strains indicated clear higher ulcer susceptibility in the MR rats noticeable in both the incidence and character of lesions. Of particular interest in this regard was the location of ulcers. While the ulceration of the Maudsley strains developed mainly in the antrum, no lesions ever appeared in this part of the stomach of Sprague-Dawley and Wistar strains.

\section{REFERENCES}

ADER, R., BEELS, C. C., \& TATUM, R. Blood pepsinogen and gastric erosions in the rat. Psychosomatic Medicine, 1960, 22, 1-12.

BROADHURST, P. L. Experiments in psychogenetics: Applications of biometrical genetics to the inheritance of behavior. In H. J. Eysenck (Ed.), Experiments in personality. Vol. 1. Psychogenetics and psychopharmacology. London: Routledge \& Kegan Paul, 1960. Pp. 1-102.

CANNON, W. B. Bodily changes in pain, hunger, fear and rage. New York: Appleton, 1915.

CUSHING, H. Peptic ulcers and the interbrain. Surgery, Gynecology, and Obstetrics, 1932 $55,1-34$.

EYSENCK, H. J., \& BROADHURST, P. L. Experiments with animals: Introduction. In $\mathrm{H}$ J. Eysenck (Ed.), Experiments in motivation. Oxford: Pergamon Press, 1964. Pp. 285-291.

FRANCOIS, G. R., \& SINES, J. O. Stress induced stomach lesion as related to destruction of the sympathetic ganglia. Journal of Psychosomatic Research, 1961, 5, 191-193.

GELLHORN, E., \& LOOFBOURROW, G. N. Emotions and emotional disorders, a neurophysiological study. New York: Hoeber, 1963. HALL, C. S. Emotional behavior in the rat. I. Defecation and urination as measures of individual differences in emotionality. Journal of Comparative Psychology, 1934, 18, 385-403.

JAY, G. E., JR. Genetic strains and stocks. In W. J. Burdette (Ed.), Methodology in mammalian genetics. San Francisco: Holden-Day, 1963. Pp. 83-126.

LABORATORY ANIMALS CENTRE, Catalogue of uniform strains of laboratory animals maintained in Great Britain. (2nd ed.) London: Laboratory Animals Centre, 1958.

LINDSLEY, D. B. Emotion. In S.S. Stevens (Ed.), Handbook of experimental psychology. New York: Wiley, 1951.
MIKHAIL, A. A. A study of the effects of anxiety on the recovery from gastric ulceration in emotionally reactive strains of rats. Unpublished doctoral dissertation, University of London, 1966.

MIKHAIL, A. A., \& BROADHURST, P. L. Stomach ulceration and emotionality in selected strains of rats. Journal of Psychosomatic Research, 1965, 8, 477-479.

MIKHAIL, A. A., \& HOLLAND, H.C. A simplified method of inducing stomach ulcers. Journal of Psychosomatic Research, 1966a, 9, 343-347.

MIKHAIL, A. A., \& HOLLAND, H. C. Evaluating and photographing experimentally induced stomach ulcers. Journal of Psychosomatic Research, 1966b, 9, 349-353.

SAVAGE, R. D., \& EYSENCK, H. J. Experiments with animals: The definition and measurement of emotionality. In H. J. Eysenck (Ed.) Experiments in motivation. Oxford: Pergamon Press, 1964. Pp. 292-314.

SAWREY, W. L., \& LONG, D. H. Strain and sex differences in ulceration in the rat. Journal of Comparative \& Phy siological Psychology, 1962, 55, 603-605.

SINES, J. O. Selective breeding for development of stomach lesions following stress in the rat. Journal of Comparative \& Physiological Psychology, 1959, 52,615-617.

SINES, J. O. Strain differences in activity, emotionality, body weight and susceptibility to stress induced stomach lesions. Joumal of Genetic Psychology, 1962, 101, 209-216.

SKORYNA, S.C. (Ed.), Pathophysiology of peptic ulcer. Philadelphia: Lippincott, 1963.

\section{NOTES}

1. This study was supported in part by Grant No. APA-197 (07-195-43) from the National Research Council of Canada.

2. Present address: Department of Psychology, University of Manitoba, Winnipeg, Canada.

\section{Blood pH as a possible hunger cue: Negative evidence'}

RANDAL D. BEATON, University of
Washington, Seattle, Wash. 98115

An investigation was made into the role of blood $\mathrm{pH}$ in the regulation of food intake. Rats were each subjected to five treatments: acid injection, base injection, two saline injections, and no-injection control. Eating behavior was monitored directly after these treatments. The negative results indicated that blood pH probably does not serve as a hunger cue.

The inability of present theories of hunger regulation to account for all of the available data suggests that perhaps some chemical cue plays a yet undiscovered role in hunger regulation (Smith, 1966). Hydrogen ion concentration of the blood (usually talked of in terms of its $\mathrm{pH}$ or negative logarithmic function) is here investigated as that possible chemical cue.

Upon ingestion of foodstuffs, the parietal cells of the stomach's lining produce a concentrated $\mathrm{HCl}$ secretion which enters the stomach and, at the same time, bicarbonate ions which enter the blood. It has been shown that blood leaving the stomach during gastric secretion is significantly more alkaline than the entering blood, thus accounting for the post-meal "alkaline tide" of blood pH found in humans (Hubbard, 1927) and in dogs (Gyorgy \& Kleinschmidt, 1927).

Thus, while blood $\mathrm{pH}$ and eating do 